\title{
From surface acidity to surface reactivity; inhibition of oxide dissolution
}

\author{
Dedicated to Paul W. Schindler on his retirement
}

Werner Stumm

Swiss Federal Institute for Environmental Science and Technology, EAWAG, ETHZ, CH-8600 Dübendorf, Switzerland

Key words: Surface complexation, inhibition, dissolution, iron oxide, $\mathrm{Cr}(\mathrm{III})$, phosphate, borate.

\begin{abstract}
Paul Schindler's early work on the acid-base chemistry of oxides was instrumental for the development of the concept of surface complexation. This approach has not only been important in establishing a theory on the adsorption of metal ions and ligands as a function of $\mathrm{pH}$ and solution variables, but has become essential in establishing surface speciation (coordinative structural and electronic arrangement at the solidwater interface) which in turn determines surface reactivity. The factors that affect dissolution of $\mathrm{Fe}$ (III) (hydr)oxides and inhibition of dissolution are discussed. A few examples for the inhibition of reductive and ligand-promoted dissolution by binuclear complexes of oxoanions (phosphate, borate) and of protonpromoted dissolution by $\mathrm{Cr}(\mathrm{III})$ are given.
\end{abstract}

\section{Introduction}

The seminal papers on the acid-base chemistry of hydrous oxides by Schindler and his coworkers (Schindler and Kamber, 1968; Schindler and Gamsjäger, 1972) were instrumental for the initiation of the surface complexation approach in which both specific chemical interactions of solutes with functional groups and nonspecific effects (the influence of surface charge) were taken into account. Geochemists and environmental engineers looked at surface complexation theory primarily as a pragmatic answer to the question of the distribution of a solute between the aqueous solution and the solid surface. But Schindler and his colleagues were motivated more by ideas on chemical bonding and how chemistry and physics come together at the solid-water interface. This brief discourse illustrates how important a better appreciation of the structural, coordinative, and configurational electronic bonding arrangements at the solid water interface is for understanding surface reactivity.

It has been shown in the past decade that the rates of processes such as precipitation (heterogeneous nucleation and surface precipitation), dissolution of mineral phases - of importance in the weathering of rocks, in the formation of soils and the corrosion and passivity of metals and building materials -, and catalysis (e.g. of redox processes) are kinetically surface controlled and thus critically dependent on the surface species and their 


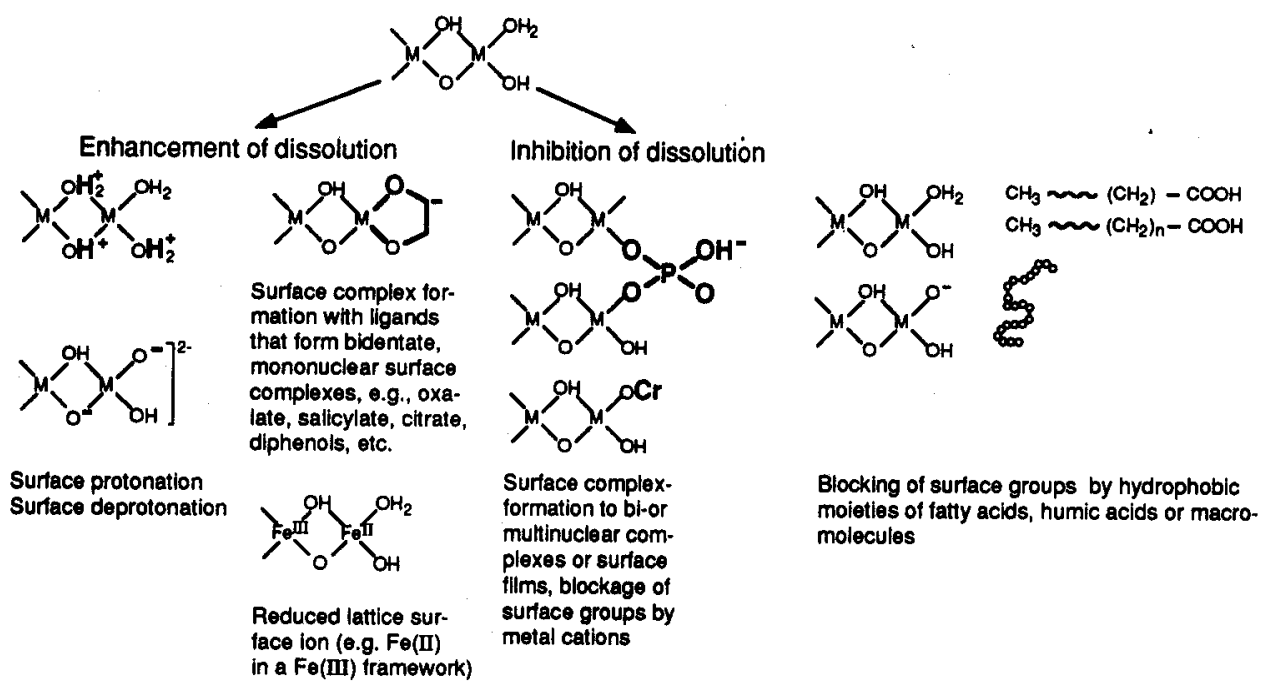

Figure 1. Schematic representation of effects of protonation, complex formation with ligands and metal ions, and reduction, on dissolution rate. The structure given here are schematic short hand notations to illustrate the principal features. Charges given are relative. Modified from Stumm (1992).

structural identity. The surface coordinative chemical model of mineral dissolution - surface chemical interaction with $\mathrm{H}^{+}, \mathrm{OH}^{-}$, metal ions and ligands to form an array of surface complexes whose reactivities determine the mechanism of many surface-controlled processes - has been successfully applied to interpret and quantify proton and ligand dependent dissolution rates of oxides and silicates.

In this paper I will give some examples illustrating that there are factors that retard dissolution, and I will discuss briefly some ideas on the nature of dissolution inhibiting coordinative surface arrangements. Figure 1 gives a simplified scheme of some of the factors which enhance or inhibit dissolution. For a general treatment of surface reactivity the reader is referred to Pulver et al. (1984), Furrer and Stumm (1986), Wieland et al. (1988), Stumm (1992) and for inhibition to Biber et al. (submitted).

\section{Dissolution and inhibition}

Several pathways may contribute to overall dissolution reactions. Surface reactivity (e.g., with regard to dissolution processes) is kinetically controlled by the structural and coordinative arrangements around the metal centers in the surface lattice, above all the coordinative arrangement of the active sites, the type of bonding with the central metal ion and the electronic configuration of the surface complexes and the surface charge. Certain solutes, so-called inhibitors, may interact with the surface upon adsorption and modify the surface coordination. This modification in turn may alter the relative importance of the contributing pathways, retarding the dissolution.

The overall dissolution rate of a mineral, $R_{\text {tot }}$ (e.g., in $\mathrm{mol} \mathrm{m}^{-2} \mathrm{~h}^{-1}$ ) is the sum of all the different parallel dissolution rates of the various metal centers. In this case each metal cen- 
ter may reflect a different surface species. The equation should include, in addition to the effects of protons, hydroxide ions, metal ions and ligands, the effects of reductants and inhibitors (Biber et al., submitted):

$$
\mathrm{R}_{\mathrm{tot}}=\mathrm{k}_{\mathrm{H}}\left(\mathrm{C}_{\mathrm{H}}^{\mathrm{S}}\right)^{\mathrm{n}}+\sum_{\mathrm{i}} \mathrm{k}_{\mathrm{Li}} \mathrm{C}_{\mathrm{Li}}^{\mathrm{S}}+\sum_{\mathrm{i}} \mathrm{k}_{\mathrm{Ii}} \mathrm{C}_{\mathrm{Ii}}^{\mathrm{s}}+\sum_{\mathrm{i}} \mathrm{k}_{\mathrm{Ri}} \mathrm{C}_{\mathrm{Ri}}^{\mathrm{S}}+\mathrm{k}_{\mathrm{OH}}\left(\mathrm{C}_{\mathrm{OH}}^{\mathrm{S}}\right)^{\mathrm{m}}+\sum_{\mathrm{i}} \mathrm{k}_{\mathrm{Mi}} \mathrm{C}_{\mathrm{Mi}}^{\mathrm{S}}+\mathrm{k}_{\mathrm{aq}}
$$

The terms in this equation represent the contribution made to the dissolution rate by each surface site covered with a ligand, $\sum_{\mathrm{i}} \mathrm{k}_{\mathrm{Li}} \mathrm{C}_{\mathrm{Li}}^{\mathrm{S}}$, an inhibitor, $\Sigma_{\mathrm{i}} \mathrm{k}_{\mathrm{li}} \mathrm{C}_{\mathrm{Ii}}^{\mathrm{S}}$, a metal ion (other than the central ion), $\sum_{\mathrm{i}} \mathrm{k}_{\mathrm{Mi}} \mathrm{C}_{\mathrm{Mi}}^{\mathrm{S}}$, or a reductant, $\sum_{\mathrm{i}} \mathrm{k}_{\mathrm{Ri}} \mathrm{C}_{\mathrm{Ri}}^{\mathrm{s}}$. The terms $\mathrm{k}_{\mathrm{H}}\left(\mathrm{C}_{\mathrm{H}}^{\mathrm{s}}\right)^{\mathrm{n}}$, and $\mathrm{k}_{\mathrm{OH}}\left(\mathrm{C}_{\mathrm{OH}}^{\mathrm{s}}\right)^{\mathrm{m}}$, represent acid and basic dissolution, respectively. The last term in Eq. (1) is due to the effect of hydration, and reflects the portion of the dissolution rate that is independent of ligands and pH. Each of these terms in Eq. (1) can be interpreted in terms of the activated complex theory. In this case, for each dissolution pathway, each type of metal center complex is considered to be a precursor to the "activated" complex (Wieland et al., 1988). The "activated" complex itself can then be released, taking with it the surface metal ion (or its complex) into solution.

Since some surface sites (e.g., kinks, steps, defects) are very reactive while others are not, all the individual $\mathrm{k}$ terms in Eq. (1) include a mole fraction $x_{\mathrm{i}}$ of reactive sites. For reasons of simplicity, the model outlined here assumes that the surface area is constant, that the dissolution rate is controlled by surface reactions, and that back reactions such as nucleation and crystal growth are negligible. This implies that the active sites are continuously regenerated during dissolution. Thus, by maintaining a constant ratio $\left(x_{i}\right)$ of active sites to total sites, a steady-state condition is maintained. Although the definition of $x_{\mathrm{i}}$ is not limited to chemically and structurally equivalent surface hydroxyl groups, the theory of mean field statistics (e.g., Sposito, 1984) allows these groups to be treated as such.

This model, in agreement with experimental results, also predicts dissolution that is linear with time. Since all the dissolution reactions are parallel, usually only one or two mechanisms dominate the reaction under given conditions. As a result, of all the terms in Eq. (1), only one or two will be of importance. Because the formation of a surface complex is fast compared to its detachment into solution, it is reasonable to assume that equilibrium conditions, concerning surface complex formation, are maintained at all times. The various surface equilibrium concentrations, $C_{i}^{s}$, in Eq. (1), (extent of surface protonation, surface concentration of ligands or inhibiting species) can be experimentally determined from alkalimetric titration curves and from analytical measurements on the extent of adsorption. These concentrations may also be obtained mathematically from equilibrium constants. (Schindler and Stumm, 1987; Dzombak and Morel, 1990).

\section{Surface protonation}

The adsorption of a charged species, at constant $\mathrm{pH}$, may change the surface protonation (Sigg and Stumm, 1981; Borghi et al. 1991, Blesa et al. in preparation). The formation of a negatively charged surface complex (e.g., by adsorption of a multivalent ligand) is accompanied by an increase in surface protonation; the formation of a positively charged surface complex (e.g., due to the adsorption of a cation) is accompanied by a decrease in surface protonation. In doing so, it may cause synergistic or antagonistic effects with respect to the relative acceleration or inhibition of dissolution. For example, when a bi- 
valent anionic ligand $\mathrm{B}^{2-}$, such as a dicarboxylate ion, a diphenolate or a hydroxycarboxylate (or their conjugate acids), interacts with a central metal ion of an oxide surface to form a mononuclear inner-sphere surface complex, the electron donors of the ligand's functional groups facilitate detachment of the metal center complex ("trans"-effect). This detachment is further assisted by the increase in surface protonation that typically accompanies (despite a constant solution $\mathrm{pH}$ ) the adsorption of the ligand. The overall dissolution rate is consequently affected by a change in $\mathrm{C}_{\mathrm{H}}^{s}$ (first term in eq. (1)). The adsorption of a bivalent cation decreases surface protonation and thus usually decreases the dissolution rate under low-pH conditions and accelerates the dissolution in the higher $\mathrm{pH}$ range because of surface deprotonation. It has been shown, for example, that the binding of $\mathrm{Mg}^{2+}$ to $\mathrm{SiO}_{2}(\mathrm{~s})$ in the alkaline $\mathrm{pH}$ range increases its dissolution rate.

The formation of an outer-sphere complex has little effect on the electron distribution at the solid-water interface and, thus, is directly of no influence upon the dissolution rate; but indirectly, ion-pair formation at the surface changes surface protonation similarily as inner-sphere complexation. Furthermore, even indifferent electrolytes affect surface charge and can thus influence surface reactivity.

\section{Binuclear surface complexes}

As suggested in Fig. 1, binuclear or multi-nuclear surface complexes tend to block surface sites. A much higher activation energy is involved in detaching simultaneously two metal centers from the surface; hence dissolution is retarded by binuclear surface species. This retardation is especially pronounced when the effect of surface coordination with an inhibitor upon surface protonation, is not unfavorable. For example, in the reaction of an anionic inhibitor, $\mathrm{L}^{2-}$, e.g.,

$$
(>\mathrm{FeOH})_{2}+\mathrm{L}^{2-} \rightleftarrows(>\mathrm{Fe})_{2} \mathrm{~L}+2 \mathrm{OH}^{-}
$$

an uncharged surface complex is formed and the surface protonation is not changed; or, the adsorption of chromium(III) to an oxide in acid solution as a binuclear surface complex is accompanied by a significant decrease in surface protonation. Thus, the inhibition by blocking surface groups is synergistically enhanced by the decrease in surface protonation.

\section{Example: inhibition by oxoanions}

To exemplify inhibition effects, we choose a few case studies with Fe(III) (hydr)oxides because these oxides are readily dissolved with protons, ligands and reductants and are of great importance in the iron cycles in natural waters. The reductive dissolution of $\mathrm{Fe}$ (III) minerals by a reductant such as $\mathrm{H}_{2} \mathrm{~S}$ is much faster than ligand- or proton-promoted dissolution. The dissolution reaction, as shown by Dos Santos Afonso and Stumm (1992), is initiated by the formation of $>\mathrm{FeS}$ and $>\mathrm{FeHS}$ surface complexes; the subsequent electron transfer within the complex leads to the formation of Fe(II) centers in the surface lattice. The $\mathrm{Fe}$ (II)-O bond is characterized by a smaller Madelung energy than the $\mathrm{Fe}$ (III)-O bond (larger radius of $\mathrm{Fe}$ (II) than $\mathrm{Fe}$ (III)); therefore the $\mathrm{Fe}$ (II) is more readily detached from the surface into the solution. 
a)

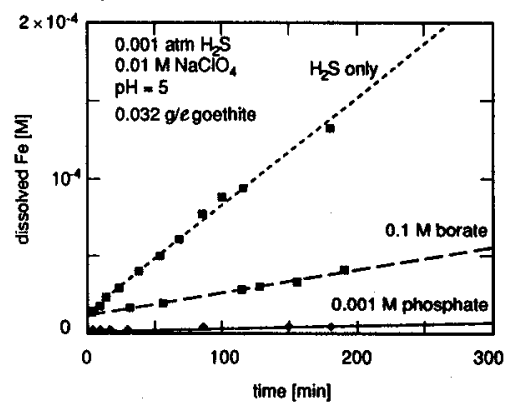

b)

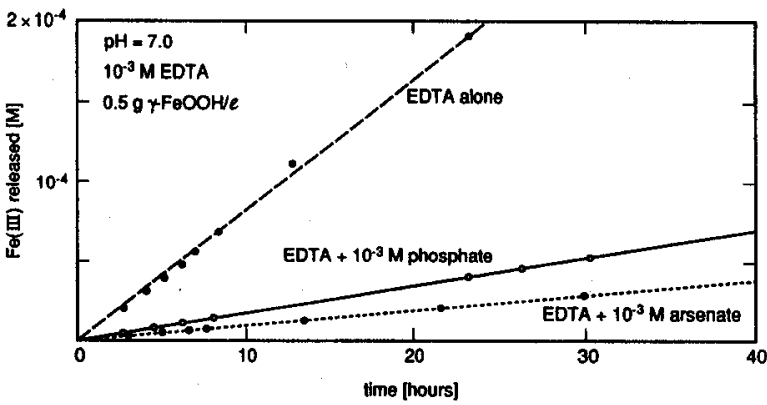

Figure 2. a) Effect of phosphate and borate on progress of reductive dissolution by $\mathrm{H}_{2} \mathrm{~S}$. $\left(10^{-2} \mathrm{M} \mathrm{NaClO}_{4}\right.$; $\mathrm{pH}=5.0$. Partial pressure of $\mathrm{H}_{2} \mathrm{~S}=10^{-3} \mathrm{~atm} .0 .032 \mathrm{gL}^{-1}$ goethite.

b) Effect of phosphate and arsenate on retarding the EDTA $\left(10^{-3} \mathrm{M}\right)$-promoted nonreductive dissolution rate of lepidocrocite $\left(0.5 \mathrm{gL}^{-1}\right)$ at $\mathrm{pH}=7.0\left(0.01 \mathrm{M} \mathrm{NaClO}_{4}\right)$.

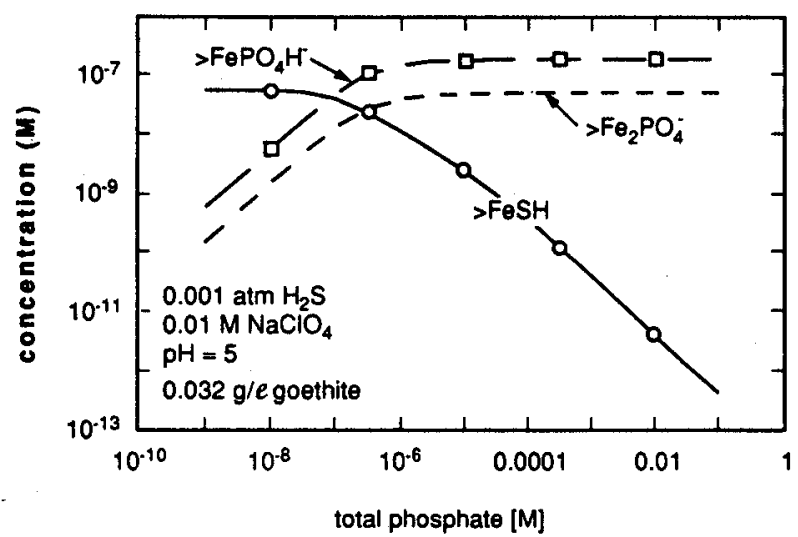

Figure 3. Surface equilibrium competition between reductant and inhibitor. Phosphate above a total concentraton of $10^{-6} \mathrm{M}$ replaces $-\mathrm{SH}$ surface groups. (0.001 atm $\mathrm{H}_{2} \mathrm{~S}, 0.01 \mathrm{M} \mathrm{NaClO}_{4}, 0.03 \mathrm{gL}^{-1}$ goethite), modified from Biber et al. (submitted).

As shown in Figure 2a, phosphate and borate inhibit the dissolution of goethite by $\mathrm{H}_{2} \mathrm{~S}$. Similarily, the dissolution of lepidocrocite $(\gamma-\mathrm{FeOOH})$ by EDTA $\left(Y^{4}\right)$ is inhibited by phosphate and arsenate (Fig. 2b). Both in the reductive dissolution (by $\mathrm{H}_{2} \mathrm{~S}$ ) and the ligand-promoted dissolution (by EDTA) the inhibition effects can be explained by ligand-exchange reactions of the type (the definive assignment of the protonation of surface species has not yet been established).

$$
\begin{aligned}
& 2>\mathrm{FeS}^{-}+\mathrm{H}_{2} \mathrm{PO}_{4}^{-}+3 \mathrm{H}^{+}=(>\mathrm{Fe})_{2} \mathrm{HPO}_{4}+2 \mathrm{H}_{2} \mathrm{~S} \\
& 2>\mathrm{FeH}_{2} \mathrm{Y}^{-}+\mathrm{H}_{2} \mathrm{PO}_{4}^{-}+\mathrm{H}^{+}=(>\mathrm{Fe})_{2} \mathrm{HPO}_{4}+2 \mathrm{H}_{3} \mathrm{Y}^{-}+
\end{aligned}
$$

The fact that oxoanions can effectively inhibit reductive and non-reductive dissolution with regard to a reference system, supports Equation (1) and the concept of competition between dissolution-promoting and dissolution-inhibiting ligands. As Figure 3 shows with 


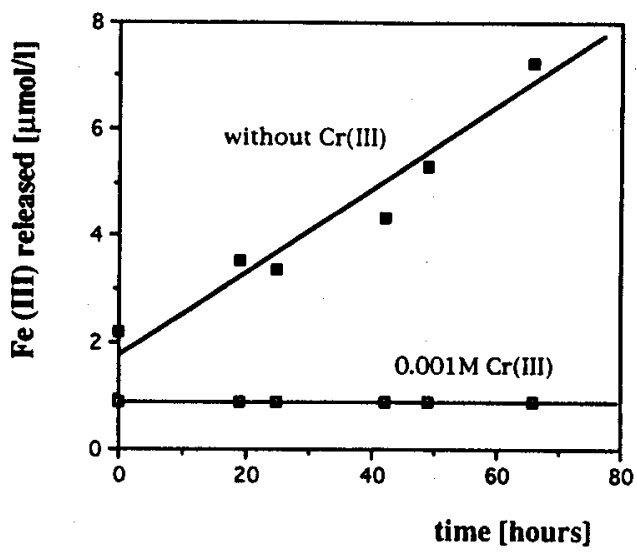

Figure 4. Effect of $10^{-3} \mathrm{M} \mathrm{Cr}(\mathrm{III})$ on the proton-promoted dissolution $(\mathrm{pH}=3)$ of $\alpha$-FeOOH $(0.5 \mathrm{~g} / \mathrm{L})$ in $0.1 \mathrm{M} \mathrm{KNO}_{3}$. (From Bondietti et al., in press.).

the help of MICROQL calculations (Westall, 1979; based on complex formation constants fitted to actual data by Sigg and Stumm (1981) and Dos Santos Afonso and Stumm (1992), the dissolution system is very sensitive to phosphate.

\section{Example: inhibition in acid solutions by $\mathrm{Cr}$ (III)}

Figure 4 shows that $\mathrm{Cr}$ (III) is a very efficient inhibitor of hematite $\left(\alpha-\mathrm{Fe}_{2} \mathrm{O}_{3}\right)$. The adsorption of $\mathrm{Cr}(\mathrm{III})$ to goethite surfaces has been investigated, using XAS, by Charlet and Manceau (1992). Scanning tunneling microscopy was used by Eggleston to study the adsorption of $\mathrm{Cr}$ (III) to hematit (001) (Eggleston and Stumm, 1993; Eggleston, this issue). These studies confirm inner-sphere adsorption, and suggest that the most stable sites for $\mathrm{Cr}$ (III) on the surfaces are associated with octahedral vacancies in the underlying oxide and, depending on surface density, show a preponderance of adsorbate clustering.

\section{ACKNOWLEDGEMENTS}

I met Paul Schindler first at a conference on "Equilibrium Concepts in Natural Water Systems" in Pittsburgh 1966. Ever since, most of my research work carries some of his "hand writing". In 1975 Paul and I presented at the National Colloid Symposium at Clarkson University in Potsdam two papers on metal ion binding on hydrous oxide surfaces introducing a concept that became to be known as the "SWISS MODEL on Surface Complexation" (Fig. 5a and b). In the discussion some participants dubbed it the "Swiss cheese model" to account for the alleged holes in the theory. As Figure 5a shows, such accusations did not bring Paul out of his Bernese reservations, but his codefender reacted with his usual, rather undiplomatic, vigor. 


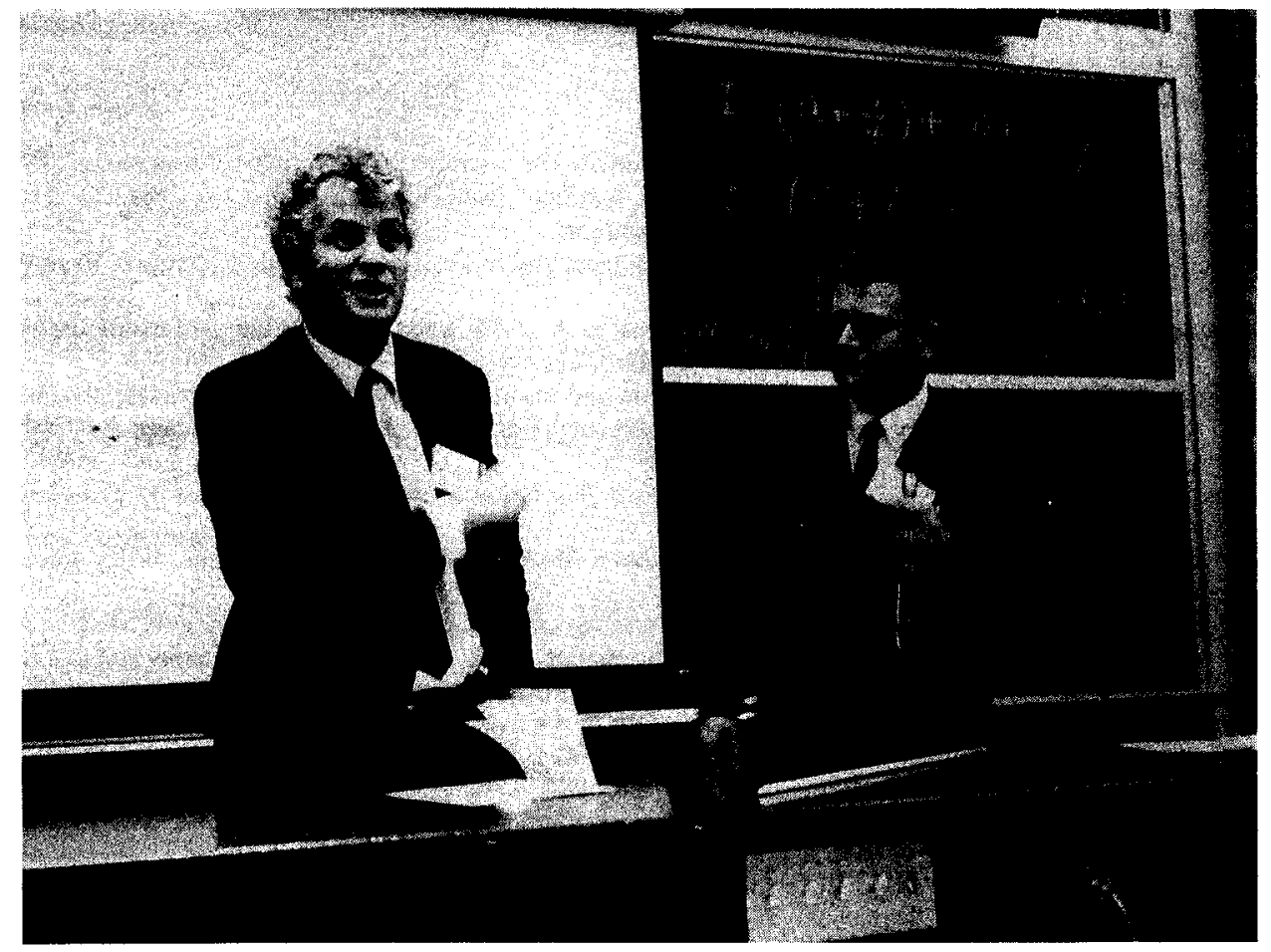

\section{A SWISS MODEL FOR ADSORPTION OF METAL}

\section{IONS AT OXIDE WATER INTERFACES}

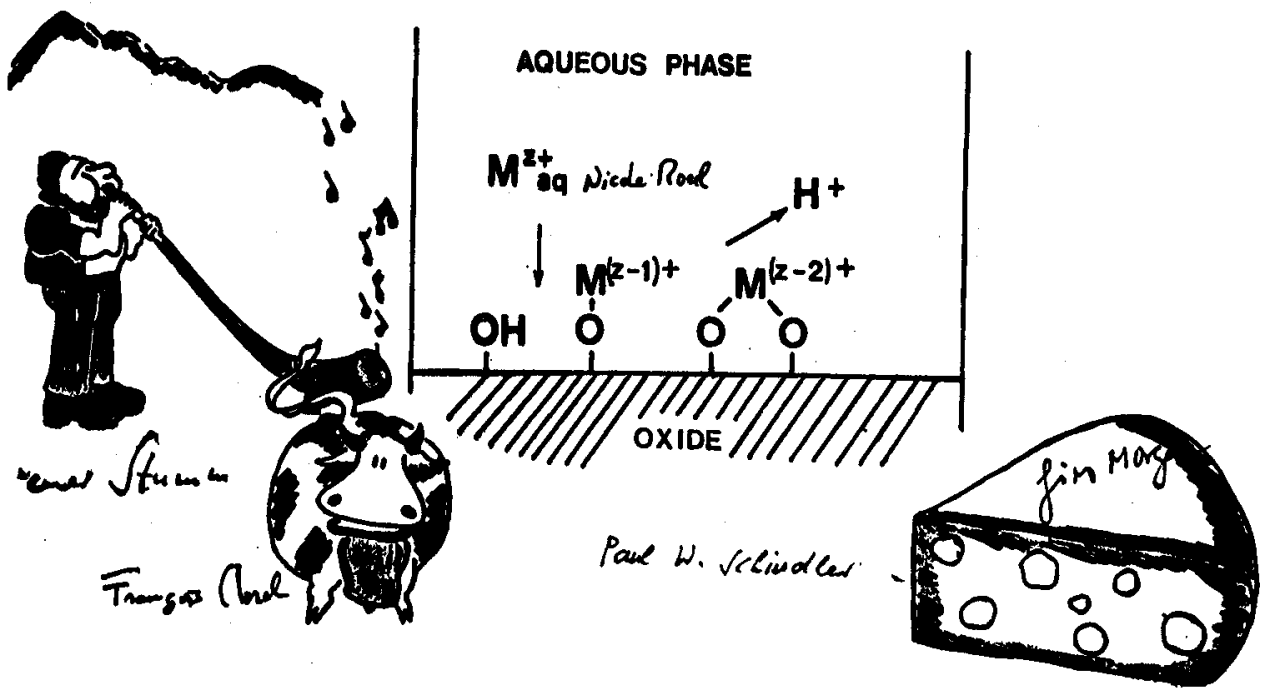

Figure 5. a) Paul Schindler (right) and Werner Stumm at the 1975 National Colloid Symposium at Clarkson University engaged vividly in a discussion on surface complexation.

b) The cartoon illustrates the "Swiss Model" on surface complexation. The signatures on the cartoon show that James J. Morgan, François M.M. Morel and Nicole Morel are "godfathers" and "godmother" to the Swiss Model. 


\section{REFERENCES}

Biber, M. Dos Santos Afonso, M., Stumm W. (submitted) The coordination chemistry of weathering: IV. Inhibition of the dissolution of oxide minerals. Geochim. Cosmochim. Acta.

Blesa, M.A., Regazzoni, A.E., Stumm, W., (in preparation).

Bondietti, G., Sinniger, J., Stumm, W. (in press) The reactivity of Fe(III) (hydr)oxides; effects of ligands in inhibiting the dissolution. Colloids and Surf.

Borghi, E. B., Regazzoni, A.E., Maroto, A.J.G., Blesa, M. A., 1988. Reductive dissolution of magnetite by solutions containing EDTA and Fe". J. Colloid Interface Sci. 130:299-310.

Charlet, L., Manceau, A., 1993. Structure, formation and reactivity of hydrous oxide particles; insights from X-ray absorption spectroscopy. In Environmental Particles (vol. 2) (ed. J. Buffle and H.P. Von Leeuwen) Lewis publ., Boca Raton, Florida.

Dos Santos Afonso, M., Stumm, W., 1992. Reductive dissolution of iron(III) (hydr)oxides by hydrogen sulfide. Langmuir, 8:1671-1675. Dzombak, D., Morel, F., 1990. Surface Complexation Modeling: Hydrous Ferric Oxide. Wiley-Inter-
science, New York.

Eggleston, C. M. and W. Stumm, 1993. Scanning tunneling microscopy of $\mathrm{Cr}(\mathrm{III})$ chemisorbed on $\alpha-\mathrm{Fe}_{2} \mathrm{O}_{3}$ (001) surfaces from aqueous solution: Direct observation of surface mobility and clustering. Geochim. Cosmochim. Acta 57:4843-4850.

Furrer, G., Stumm, W., 1986. The coordination chemistry of weathering: I. Dissolution kinetics of $\delta-\mathrm{Al}_{2} \mathrm{O}_{3}$ and BeO. Geochim. Cosmochim. Acta 50:1847-1860.

Pulver, K., Schindler, P.W., Westall, J.C., Grauer, R., 1984. Kinetics and mechanisms of dissolution of Bayerite $\left(\gamma \mathrm{Al}(\mathrm{OH})_{3}-\mathrm{HF}\right.$ solutions at $298.2^{\circ} \mathrm{K}, \mathrm{J}$. Colloid and Interf. Science 10:554-564.

Schindler, P.W., Gamsjäger, H., 1972. Acid-base reactions of the $\mathrm{TiO}_{2}$ (Anatase)-water interface and the point of zero charge of $\mathrm{TiO}_{2}$ suspensions. Kolloid-Z. u. Z-Polymere, 250:759-763.

Schindler, P.W., Kamber, H.R., 1968. Die Acidität von Silanolgruppen, Helv. Chim. Acta $51: 1781-$ 1786.

Schindler, P., Stumm, W., 1987. The surface chemistry of oxides, hydroxides, and oxide minerals. In Aquatic Surface Chemistry, (ed. W. Stumm) pp. 83-110. Wiley-Interscience, New York. Sigg, L., Stumm, W., 1981. The interactions of anions and weak acids with hydrous goethite $(\alpha-\mathrm{FeOOH})$
surface. Colloids and Surfaces $2: 101-117$.

Sposito, G., 1984. The Surface Chemistry of Soils. Oxford Univ. Press.

Stumm, W., 1992. Chemistry of the Solid - Water Interface, Wiley-Interscience, New York.

Westall, J., 1979. MICROQL - I: A chemical equilibrium program in BASIC, EAWAG, Dübendorf, Switzerland.

Wieland, E., Wehrli, B., Stumm, W., 1988. The coordination chemistry of weathering: III A generalization on the dissolution rates of minerals. Geochim. Cosmochim. Acta: 48, 1969-1981.

Received 21 June 1993;

manuscript accepted 31 August 1993. 